\title{
Uso de fertilizante e tempo de permanência de mudas de batata-doce produzidas em bandejas
}

\author{
Amarílis Beraldo Rós(1), Humberto Sampaio de Araújo(1), Nobuyoshi Narita(1) e João Tavares Filho(2)
}

\begin{abstract}
${ }^{(1)}$ Agência Paulista de Tecnologia dos Agronegócios, Polo Alta Sorocabana, Rodovia Raposo Tavares, Km 561, Caixa Postal 298, CEP 19015-970 Presidente Prudente, SP. E-mail: amarilis@apta.sp.gov.br, humbertosaraujo@apta.sp.gov.br, narita@apta.sp.gov.br (2)Universidade Estadual de Londrina, Rodovia Celso Garcia Cid, Km 380, Caixa Postal 6.001, CEP 86051-980 Londrina, PR. E-mail: tavares@uel.br
\end{abstract}

\begin{abstract}
Resumo - O objetivo deste trabalho foi avaliar a produção de mudas de batata-doce em bandejas de poliestireno, com utilização de fertilizante de liberação lenta, e estabelecer o tempo adequado de permanência dessas mudas nas bandejas. Utilizou-se o delineamento experimental inteiramente casualizado, em arranjo fatorial $5 \times 5$, com cinco doses do fertilizante de liberação lenta osmocote NPK 15-09-12 $(0,50,100,150$ e $200 \mathrm{~g}$ por $25 \mathrm{~kg}$ de substrato) e cinco tempos de permanência nas bandejas (14, 28, 42, 56 e 70 dias após o plantio, DAP). Foram avaliados o número de raízes e de folhas e suas respectivas massas de matéria seca. Além disso, avaliou-se a integridade dos torrões em função do tempo de permanência das mudas nas bandejas, em experimento sem adição de fertilizante. Observou-se interação significativa entre doses do fertilizante e o tempo de permanência nas bandejas. A adubação com $150 \mathrm{~g}$ favoreceu o incremento do número de raízes e folhas e a massa de matéria seca das mudas, a partir de 14 DAP. Em geral, a integridade dos torrões aumenta com o tempo de permanência. Observaram-se sintomas de deficiência nutricional a partir dos $25 \mathrm{DAP}$, quando não foi utilizado fertilizante. O período de permanência em bandejas pode ser ampliado se o fertilizante de liberação lenta for utilizado.
\end{abstract}

Termos para indexação: Ipomoea batatas, enraizamento, estaca herbácea, miniestaca, multiplicação, substrato.

\section{Fertilizer use and permanence time of sweet potato plantlets produced in trays}

\begin{abstract}
The objective of this work was to evaluate the production of sweet potato plantlets in polystyrene foam trays, using slow-release fertilizer and to establish the proper permanence time for this plantlets to stay in trays. An entirely radonmized experimental design was used with $5 \times 5$ factorial arrangement, with five doses of osmocote slow-release fertilizer NPK 15-09-12 (0, 50, 100, 150 e $200 \mathrm{~g}$ per $25 \mathrm{~kg}$ of the substrate) and five permanence times in the trays $(14,28,42,56$ e 70 days after planting, DAP). The number of roots and leaves, and their respective dry matter mass were evaluated. Furthermore, clod integrity as a function of the permanence time of cuttings in trays was evaluated in an experiment without the use of fertilizers. It was observed significant interaction between fertilizer doses and permanence time in the trays. The fertilization with $150 \mathrm{~g}$ increased the number of roots and leaves and the dry matter of new plantlets, after 14 DAP. Generally, clod integrity increases with permanence time. Nutritional deficiency symptoms were observed from 25 DAP, when no fertilizer was used. The permanence time in trays may be extended if the slow-release fertilizer is used.
\end{abstract}

Index terms: Ipomoea batatas, rooting, herbaceous cutting, minicutting, multiplication, substrate.

\section{Introdução}

A implantação da cultura da batata-doce, Ipomoea batatas (L.) Lam., ocorre por meio do uso de material vegetativo. Esse material pode ser obtido de ramas de lavouras comerciais ou de plantas cultivadas em viveiro.

Para a implantação do viveiro devem-se utilizar raízes tuberosas ou ramas de plantas produtivas e sadias, visto que a seleção de materiais com boa sanidade favorece o incremento da produtividade da cultura. Em mandioca, por exemplo, a utilização de manivas de boa qualidade tem influência direta no aumento da produtividade, pois proporciona incrementos na produção da cultura de até $30 \%$, sem alteração de outras práticas culturais ou utilização de insumos (Rodrigues et al., 2008).

Em relação à batata-doce, quando há poucas plantas matrizes para o fornecimento de ramas para a implantação do viveiro, recomenda-se a produção de miniestacas em bandeja, para produção de maior número de mudas. Reghin et al. (2007) avaliaram a produção de mudas de cebola em bandejas e concluíram

Pesq. agropec. bras., Brasília, v.46, n.8, p.845-851, ago. 2011 
que esse sistema permite ao produtor dedicar maior cuidado às plântulas, pois a atividade é desenvolvida em ambiente protegido, o que facilita o controle de pragas e doenças, e proporciona elevada taxa de sobrevivência após o transplante e maior uniformidade no campo.

No entanto, mudas produzidas em bandejas podem apresentar sintomas de deficiência nutricional e ter seu desenvolvimento comprometido se o substrato não disponibilizar a quantidade exigida de nutrientes para o enraizamento adequado. Esse problema pode ser agravado se o tempo de permanência das mudas nas bandejas estender-se em demasia. A adição de fertilizantes, portanto, pode favorecer o desenvolvimento das mudas e aumentar o período de permanência delas nas bandeja, além de garantir rápido crescimento. A suplementação do substrato para mudas em recipientes, geralmente, é feita com fertilizantes de liberação lenta para reduzir problemas de excesso de disponibilidade e perdas de nutrientes por lixiviação.

O osmocote (Everris International B. V., Geldermalsen, Holanda) é um fertilizante de liberação lenta, em razão do emprego de membrana termosensível para revestimento dos grânulos. Essa membrana dissolve-se de forma gradativa conforme as variações de temperatura, mas independe da quantidade e qualidade da água aplicada (José et al., 2009).

Backes et al. (2007) trabalharam com mudas de pimenta transplantadas para vasos com substrato comercial e diferentes doses de fertilizante de liberação lenta e verificaram que o uso de fertilizante favorece o crescimento das mudas e diminui o período de tempo para atingir seu ponto comercial.

Barbizam et al. (2002) estudaram o desenvolvimento de mudas de cafeeiro em tubetes com diferentes doses de osmocote e verificaram resposta favorável ao uso de doses adequadas em todas as características analisadas, entre as quais o número de folhas, a massa de matéria seca da parte aérea e das raízes e o volume de raízes.

O objetivo deste trabalho foi avaliar a produção de mudas de batata-doce em bandejas de poliestireno, com utilização de fertilizante de liberação lenta, e estabelecer o tempo adequado de permanência dessas mudas nas bandejas.

\section{Material e Métodos}

Foram realizados dois experimentos em ambiente de viveiro com tela antiafídeo situado na Agência
Paulista de Tecnologia dos Agronegócios, Polo Alta Sorocabana, no Município de Presidente Prudente, SP, entre agosto e dezembro de 2008. Foram avaliados os efeitos de doses de fertilizante (agosto a outubro) sobre o crescimento das mudas e avaliaram-se os efeitos do tempo de permanência das mudas nas bandejas sobre a integridade dos torrões (novembro a dezembro).

Como propágulos, foram utilizados segmentos de ramas de batata-doce com dois nós, obtidos de plantas da variedade Londrina, cultivadas em campo. Os segmentos foram retirados da porção apical das ramas (até $0,6 \mathrm{~m}$ ). As folhas foram retiradas com tesoura de poda, tomando-se o cuidado de não ferir as gemas. Cada segmento foi pesado, tendo-se selecionado aqueles com massas semelhantes. Os segmentos foram imersos em solução de $5 \mathrm{~mL} \mathrm{~L}^{-1}$ de carbendazin $50 \%$, por $10 \mathrm{~min}$, para evitar doenças fúngicas.

A gema basal dos segmentos foi inserida em substrato com as diferentes doses do fertilizante osmocote NPK 15-09-12: 0, 50, 100, 150 e 200 g por $25 \mathrm{~kg}$ de substrato comercial Plantmax (Eucatex, Paulínia, SP, Brasil), produzido à base de vermiculita, acrescido de casca de pínus. Foram utilizadas bandejas com 72 células de $11 \mathrm{~cm}$ de altura e $5 \mathrm{~cm}$ de lado.

As bandejas permaneceram a $0,5 \mathrm{~m}$ do chão, sobre bancada formada por arame, o que permitiu a poda natural das raízes das mudas por desidratação. O material foi irrigado por todo o período do experimento. Cada bandeja foi composta por um tratamento (dose) e, como as bandejas possuíam 12 linhas de 6 células, foram coletadas as quatro plantas centrais das segunda, quarta, sexta, oitava e décima linhas, em cada tempo de permanência: $14,28,42,56$ e 70 dias após o plantio (DAP), respectivamente. Foram avaliados número e massa de matéria seca de raízes e folhas. Para a quantificação do número de raízes, foram consideradas aquelas que saíam diretamente do segmento de dois nós e para o número de folhas, as totalmente abertas. Para a obtenção da massa de matéria seca, o material colhido, tanto da parte aérea como das raízes, foi colocado em estufa com circulação forçada de ar, mantida à temperatura constante de $65^{\circ} \mathrm{C}$, até a obtenção de valores constantes de massa.

Adotou-se o delineamento experimental inteiramente casoalisado, em arranjo fatorial $5 \times 5$, com cinco doses de fertilizante de liberação lenta e cinco tempos de permanência, com três repetições. 
Os dados relativos à massa de matéria seca e de raízes e folhas foram transformados mediante emprego da equação $(x+0,5)^{0,5}$, em razão da presença de valores próximos a zero. Os dados obtidos foram submetidos a análises de variância e as médias foram ajustadas a equações de regressão polinomial. Os critérios para a escolha do modelo foram a significância pelo teste $\mathrm{F}$, a $5 \%$ de probabilidade, e os maiores valores do coeficiente de determinação $\left(\mathrm{R}^{2}\right)$. Os pontos de máximo foram determinados por derivação das equações de regressão.

Para a avaliação da integridade de torrões, os segmentos de ramas de batata-doce foram plantados com uso dos mesmos procedimentos descritos anteriormente, mas sem adição de fertilizante. Utilizouse delineamento experimental inteiramente casualisado, com seis tratamentos e cinco repetições. Foram utilizadas bandejas de 72 células e as avaliações foram feitas em seis tempos de permanência. Cada parcela foi constituída por cinco bandejas, tendo sido coletadas as quatro plantas centrais das primeira, terceira, quinta, sétima, nona e décima primeira linhas de cada bandeja, aos 16, 24, 32, 40, 48 e 56 DAP, respectivamente. Assim, em cada tempo de permanência foram avaliadas 20 mudas por parcela. As mudas da primeira linha não apresentaram necessidade de bordadura, pois, até o tempo de sua coleta, suas folhas não apresentavam tamanho suficiente para proporcionar sombreamento nas mudas ao redor.

Em cada tempo de permanência foi quantificada a percentagem de plantas com torrões classificados nas seguintes classes de integridade: menor que $30 \%$, entre 30 e $50 \%$, entre 50 e $70 \%$, entre 70 e $90 \%$ e maior que $90 \%$. A inclusão dos torrões nas classes foi realizada por meio de avaliação visual. Os torrões estavam úmidos quando foram retirados das bandejas.

Os dados obtidos foram transformados mediante emprego da equação $(\mathrm{x}+0,5)^{0,5}$ em razão da presença de valores zero e submetidos a análises de variância, com as médias ajustadas a equações de regressão polinomiais, a $5 \%$ de probabilidade.

\section{Resultados e Discussão}

Houve interação significativa entre as doses do fertilizante e os tempos de permanência, em todas as características estudadas.

O número de raízes foi influenciado pela aplicação do fertilizante somente a partir do tempo de permanência de 42 DAP (Figura 1). Nesse tempo, o número de raízes apresentou incremento linear com o aumento das doses do fertilizante, ou seja, a quantidade de nutrientes liberada não foi suficiente para causar efeito depressivo à característica. Aos 56 e 70 DAP, $\mathrm{o}$ incremento do número de raízes atingiu o ponto máximo com as doses de 160 e $118 \mathrm{~g}$ de fertilizante por $25 \mathrm{~kg}$ de substrato, respectivamente. A dose em que houve máxima resposta, aos $56 \mathrm{DAP}$ causou efeito depressivo aos 70 DAP, o que pode ser consequência
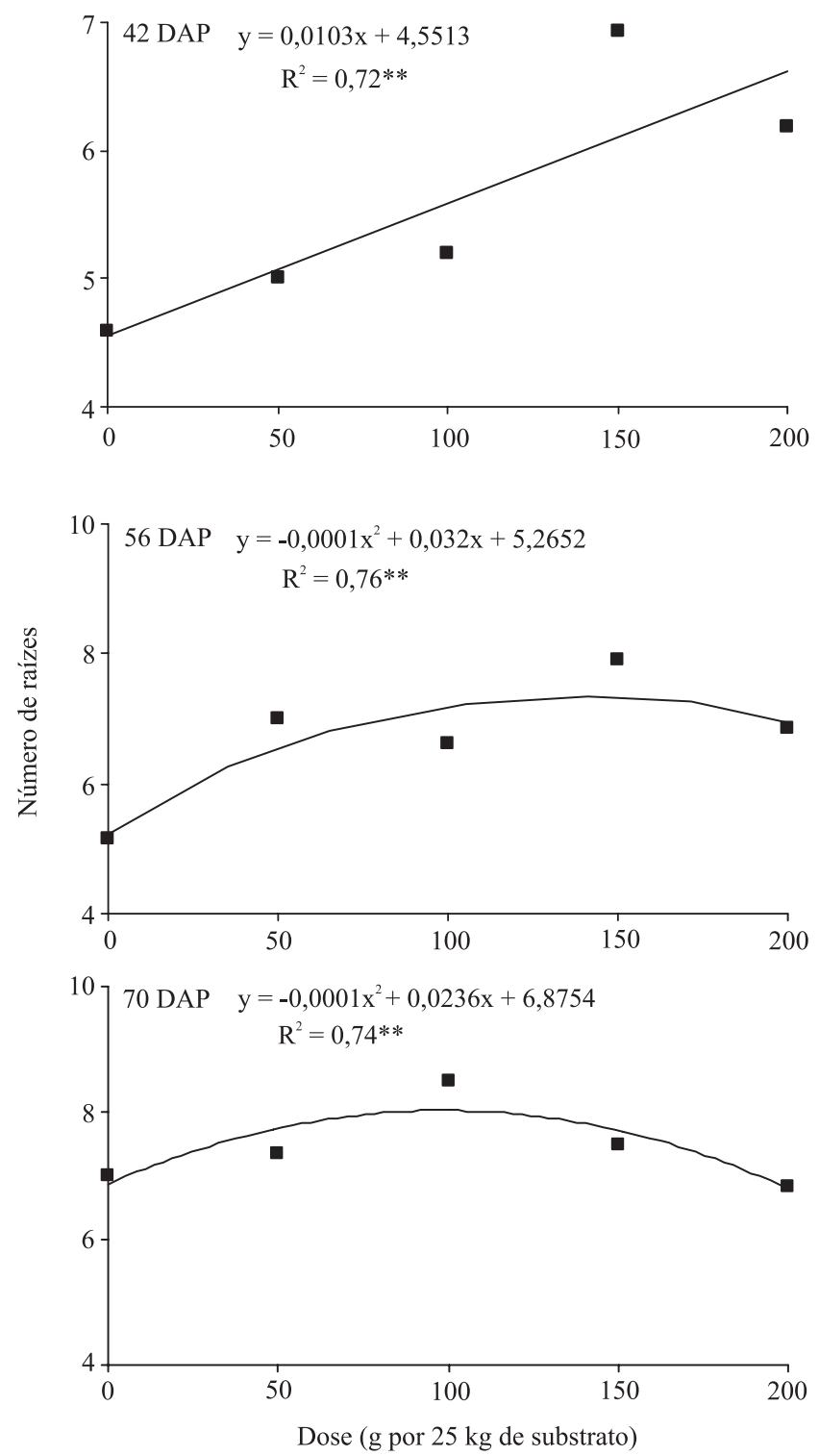

Figura 1. Número de raízes de mudas de batata-doce aos 42, 56 e 70 dias após o plantio (DAP), em razão de doses de fertilizante de liberação lenta. **Significativo a $1 \%$ de probabilidade, pelo teste F. 
da maior quantidade de nutrientes disponível para as mudas aos 70 DAP, possivelmente em razão da liberação lenta do fertilizante, o que teria resultado em concentrações desfavoráveis ao crescimento nesse tempo de permanência.

A massa de matéria seca de raízes não foi influenciada pela adição de fertilizante aos 14 e 28 DAP (Figura 2). Aos 42, 56 e 70 DAP, essa variável apresentou incremento até as doses de 150,135 e $140 \mathrm{~g}$ por $25 \mathrm{~kg}$
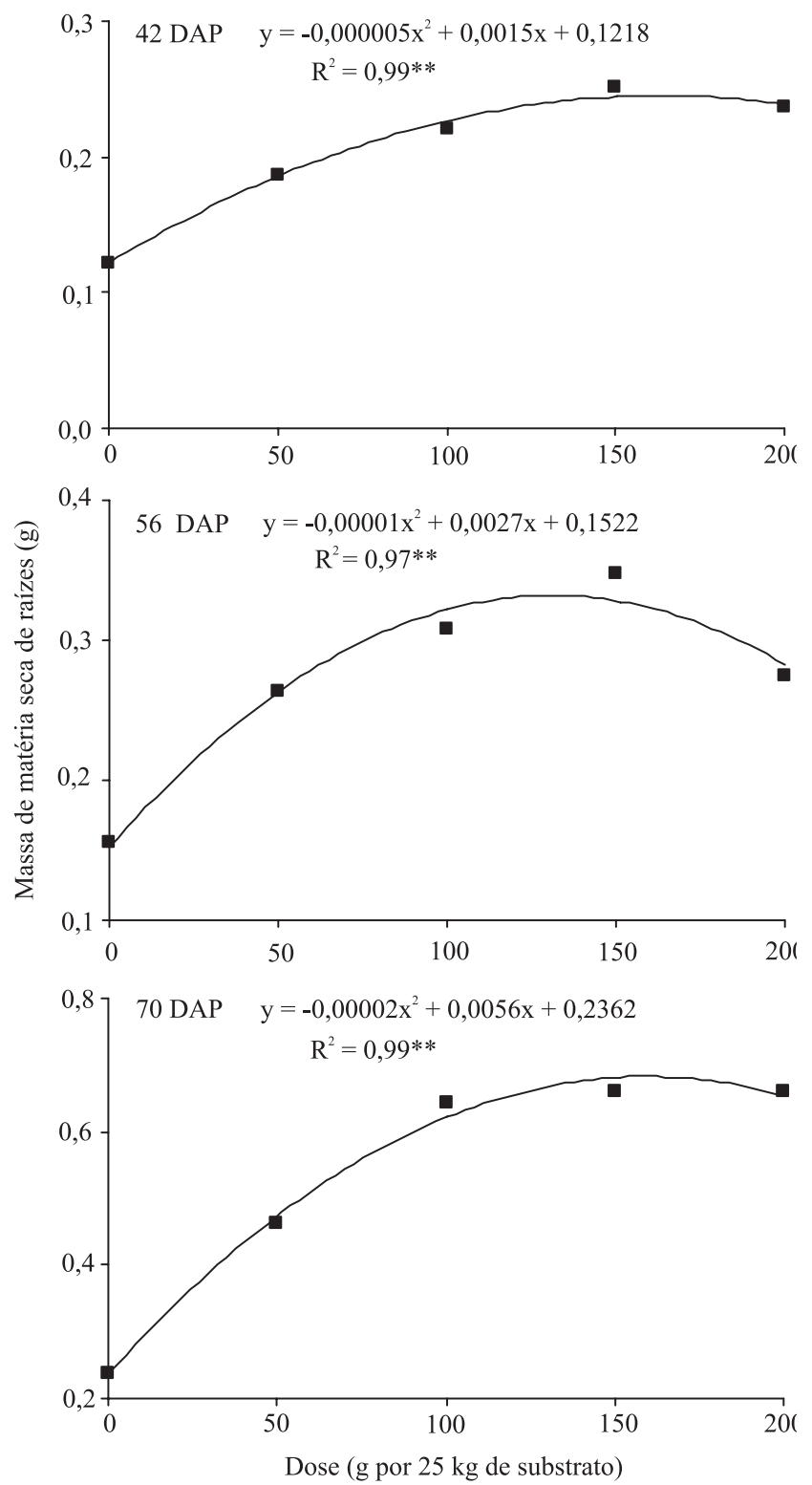

Figura 2. Massa de matéria seca de raízes de mudas de batatadoce aos 42, 56 e 70 dias após o plantio (DAP), em função de doses de fertilizante de liberação lenta. **Significativo a $1 \%$ de probabilidade, pelo teste $\mathrm{F}$. de substrato, respectivamente, tendo ocorrido efeito depressivo a partir dessas doses. Mendonça et al. (2008) também verificaram o mesmo comportamento em raízes de mudas de tamarindo cultivadas em substrato enriquecido com fertilizante de liberação lenta. Contudo, Mendonça et al. (2004) observaram que a massa de matéria seca de raízes de mudas de maracujazeiro, em substratos com fertilizante de liberação lenta, apresentou resposta segundo modelo linear crescente em função do incremento das doses.

Quando se relacionaram o número e a massa de matéria seca de raízes, verificou-se, aos 42 DAP, o incremento de raízes com o aumento das doses, porém, observou-se acréscimo de massa de matéria seca somente até a dose de $150 \mathrm{~g}$ por $25 \mathrm{~kg}$ de substrato, o que indica que a partir dessa dose há o aumento do número de raízes, mas essas se encontram com menor massa individual média. Aos 56 DAP, o número de raízes aumentou até a dose estimada de $160 \mathrm{~g}$ por $25 \mathrm{~kg}$ de substrato, enquanto a massa de matéria seca respondeu positivamente até $135 \mathrm{~g}$ por $25 \mathrm{~kg}$ de substrato. Ou seja, pode-se considerar que a dose de $150 \mathrm{~g}$ por $25 \mathrm{~kg}$ de substrato foi adequada para ambas as características, nesse tempo de permanência. De maneira semelhante, aos 70 DAP, a dose estimada de $135 \mathrm{~g}$ por $25 \mathrm{~kg}$ de substrato foi adequada para as duas características avaliadas.

Houve aumento linear no número de folhas com o aumento na dose de fertilizante aos 28 e 42 DAP (Figura 3), isto é, nesses tempos de permanência, o fertilizante não liberou quantidade de nutrientes prejudicial às mudas em nenhuma das doses aplicadas. No entanto, aos 56 e 70 DAP, o incremento do número de folhas ocorreu até as doses aproximadas de 145 e $170 \mathrm{~g}$ de fertilizante por $25 \mathrm{~kg}$ de substrato, respectivamente, o que evidencia o efeito negativo do excesso de fertilizante sobre a característica.

Aos 28 DAP, a massa de matéria seca de folhas respondeu positiva e linearmente ao incremento da dose do fertilizante (Figura 4). Contudo, aos 42, 56 e 70 DAP, a característica apresentou máxima resposta nas doses de 170, 170 e $190 \mathrm{~g}$ de fertilizante por $25 \mathrm{~kg}$ de substrato, respectivamente.

Com esses resultados, pode-se inferir que, aos 28 DAP, o acréscimo no número de folhas com as doses de fertilizante resultou em acréscimo da massa de matéria seca das folhas às mesmas doses. Aos 42 DAP, houve o aumento do número de folhas associado à menor massa de matéria seca individual 


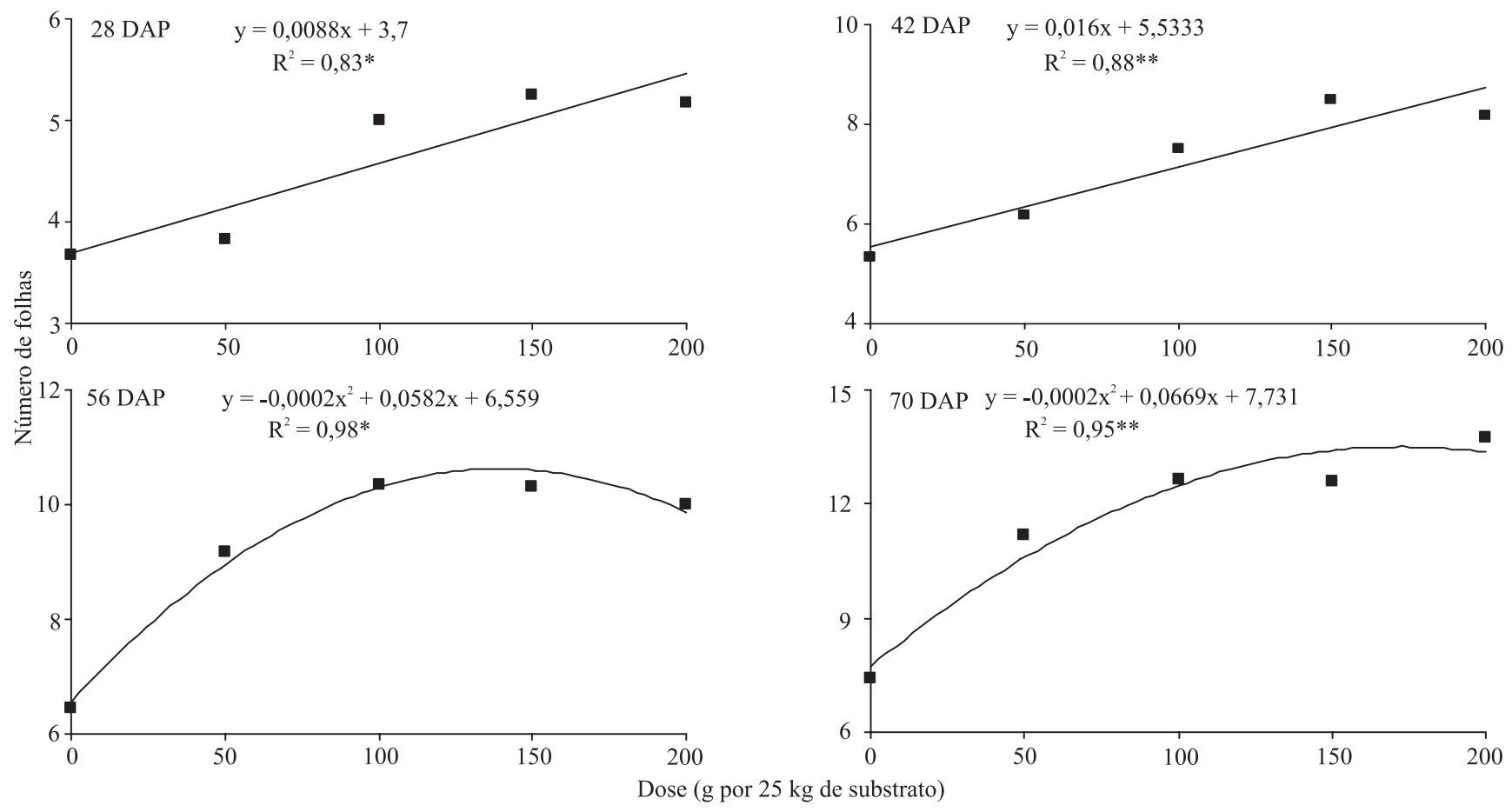

Figura 3. Número de folhas de mudas de batata-doce aos $28,42,56$ e 70 dias após o plantio (DAP), em razão de doses de fertilizante de liberação lenta. * e**Significativo a 5 e $1 \%$ de probabilidade, respectivamente, pelo teste $\mathrm{F}$.
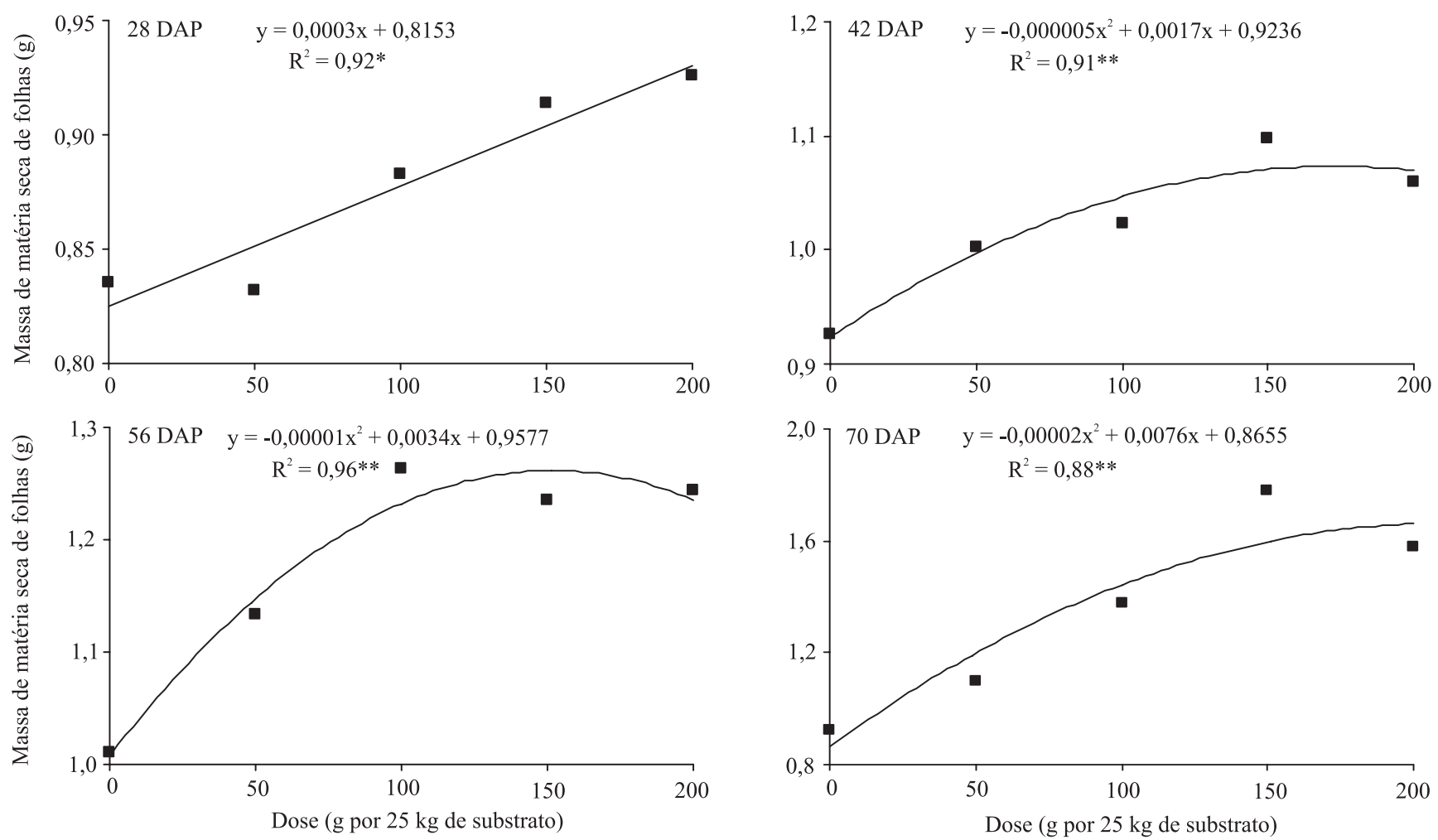

Figura 4. Massa de matéria seca de folhas de mudas de batata-doce aos 28, 42, 56 e 70 dias após o plantio (DAP), em função de doses de fertilizante de liberação lenta. * e**Significativo a 5 e $1 \%$ de probabilidade, pelo teste $\mathrm{F}$, respectivamente. 
de folhas, visto que, a partir da dose de $170 \mathrm{~g}$ por $25 \mathrm{~kg}$ de substrato, o fertilizante liberou quantidade de nutrientes prejudicial ao ganho de massa de matéria seca das folhas, mas continuou a favorecer o incremento em seu número. Aos 56 DAP, a partir de aproximadamente $145 \mathrm{~g}$ por $25 \mathrm{~kg}$ de substrato, o número de folhas diminuiu, mas dessa dose até $170 \mathrm{~g}$ por $25 \mathrm{~kg}$ de substrato, a massa de matéria seca individual de cada folha aumentou. O mesmo ocorreu aos 70 DAP, com as doses de 170 a $190 \mathrm{~g}$ por $25 \mathrm{~kg}$ de substrato.

A resposta do número de folhas a doses de fertilizante segundo o modelo quadrático é frequente. Backes et al. (2007) também verificaram esse comportamento em trabalho com mudas de pimenta transplantadas em vasos que continham substrato comercial com diferentes doses de fertilizante de liberação lenta. O mesmo fato ocorreu com mudas de maracujá oriundas de sementes produzidas em saquinhos de polietileno, que responderam negativamente a dosagens elevadas de fertilizante (Mendonça et al., 2007).

De acordo com Pereira et al. (2000), em estudo com maracujazeiro, Yamanishi et al. (2004), com mamoeiro, Scivittaro et al. (2004), com porta-enxerto de citros Poncirus trifoliata, e Teixeira et al. (2009), com dendezeiro, a adição de fertilizante de liberação lenta resulta em aumento de massa de matéria seca e também em maiores teores de nutrientes como $\mathrm{N}, \mathrm{K}$ e $\mathrm{Mg}$ nos tecidos.

De maneira geral, sem a aplicação de fertilizante de liberação lenta, as características avaliadas apresentaram menor crescimento em comparação aos tratamentos com adubação. Tal fato indica a necessidade de complementação nutricional para um bom desenvolvimento das mudas de batata-doce em bandeja. Até 14 DAP, as exigências nutricionais das mudas foram supridas pelos nutrientes presentes no substrato, não tendo havido resposta à aplicação de fertilizante. Contudo, a partir de 25 DAP, foram verificados sintomas visuais de deficiência nutricional nas mudas produzidas em substrato não adubado.

$\mathrm{Na}$ avaliação do tempo adequado de permanência das mudas nas bandejas (Figura 5), verificou-se que, aos 16 DAP, houve a predominância (70\%) de torrões pertencentes à classe com integridade inferior a $30 \%$. A percentagem dos torrões pertencentes à classe inferior a $30 \%$ de integridade decresceu com o incremento do tempo de permanência das mudas na bandeja até 38 DAP, quando atingiu valor próximo a zero. A percentagem de torrões pertencentes à classe com integridade entre 30 e $50 \%$ também decresceu em consequência do tempo de permanência. Aos 16 DAP, esses torrões corresponderam a $4 \%$ do total de torrões avaliados, valor que decresceu gradativamente até que essa classse não mais ocorresse aos 52 DAP. A quantidade de torrões pertencentes à classe com integridade entre 50 e $70 \%$ ajustou-se a um modelo cúbico. Aos 16 DAP, esses torrões corresponderam a aproximadamente $1,5 \%$ dos torrões avaliados, atingiram $8 \%$ de ocorrência aos 26 DAP e, a partir dessa data, a ocorrência dessa classe de torrões diminuiu e não mais ocorreu após 44 DAP. Os torrões pertencentes à classe com integridade entre 70 e $90 \%$ também apresentaram queda proporcional ao tempo de permanência das mudas na bandeja. Aos 16 DAP, corresponderam a $11 \%$ dos torrões e, a partir de 53 DAP, não mais ocorreram. A ocorrência dos torrões da classe com integridade superior a $90 \%$ aumentou em razão do tempo de permanência. Aos 16 DAP, os torrões com elevada integridade corresponderam a aproximadamente 9\% e, já aos 32 DAP, atingiram 78\%. Na última época de coleta, eles corresponderam a aproximadamente $98 \%$ dos torrões. Portanto, quanto maior o período de tempo das mudas no substrato, maior a retenção de substrato, visto que as raízes ocupam maior porção da célula da bandeja.

Como foram verificados sintomas de deficiência nutricional a partir de aproximadamente $25 \mathrm{DAP}$, pela não utilização de fertilizante, pode-se recomendar a retirada dos torrões entre 25 e $30 \mathrm{DAP}$, quando o

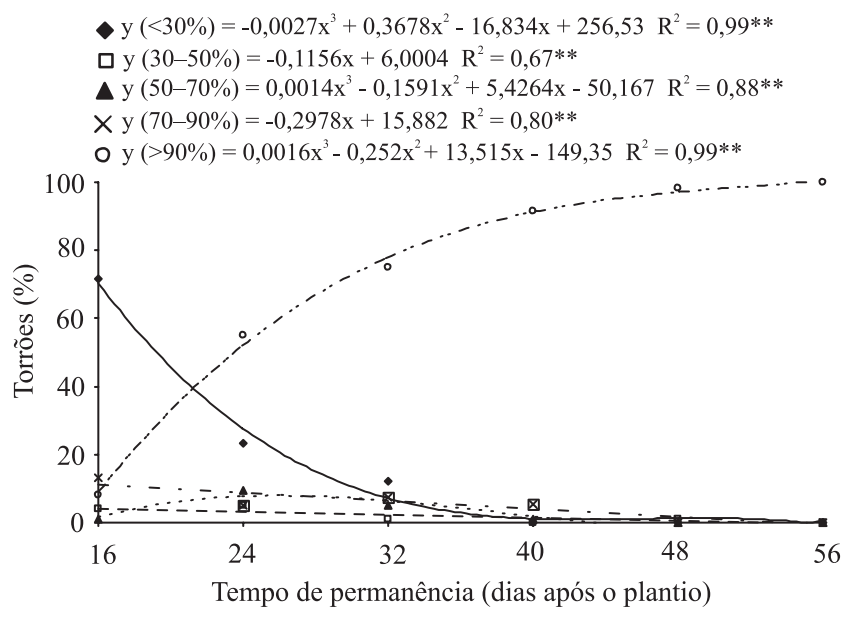

Figura 5. Percentagem de classes de integridade de torrões, em função do tempo de permanência em bandeja. **Significativo a $1 \%$ de probabilidade pelo teste $\mathrm{F}$. 
somatório das percentagens de torrões pertencentes às classes de integridade de 70 a $90 \%$ e maior do que $90 \%$ já se encontra elevado (entre aproximadamente 65 e $80 \%$ respectivamente) e os sintomas de deficiência nutricional estão em fase inicial.

\section{Conclusões}

1. Fertilizantes de liberação lenta podem ampliar o período de permanência das mudas de batata-doce nas bandejas sem que haja prejuízo ao seu crescimento.

2. As mudas de batata-doce devem ser removidas das bandejas por volta de 25 a 30 dias após o plantio, quando não são aplicados fertilizantes de liberação lenta ao substrato.

\section{Referências}

BACKES, C.; FERNANDES, F.M.; KROHN, N.G.; LIMA, C.P.; KIIHL, T.A.M. Produção de pimenta ornamental em função de substratos e doses de adubação com fertilizantes de liberação lenta e tradicional. Scientia Agraria Paranaensis, v.6, p.67-76, 2007.

BARBIZAN, E.L.; LANA, R.M.Q.; MENDONÇA, F.C.; MELO, B. de; SANTOS, C.M. dos; MENDES, A.F. Produção de mudas de cafeeiro em tubetes associada a diferentes formas de aplicação de fertilizantes. Ciência e Agrotecnologia, p.1471-1480, 2002. Edição especial.

JOSÉ, A.C.; DAVIDE, A.C.; OLIVEIRA, S.L. de. Efeito do volume do tubete, tipo e dosagem de adubo na produção de mudas de aroeira (Schinus terebinthifolia Raddi). Agrarian, v.2, p.73-86, 2009.

MENDONÇA, V.; ABREU, N.A.A. de; SOUZA, H.A. de; TEIXEIRA, G.A.; HAFLE, O.M.; RAMOS, J.D. Diferentes ambientes e osmocote na produção de mudas de tamarindeiro (Tamarindus indica). Ciência e Agrotecnologia, v.32, p.391-397, 2008.
MENDONÇA, V.; RAMOS, J.D.; GONTIJO, T.C.A.; MARTINS, P.C.C.; DANTAS, D.J.; PIO, R.; ABREU, N.A.A. de. Osmocote e substratos alternativos na produção de mudas de maracujazeiro-amarelo. Ciência e Agrotecnologia, v.28, p.799-806, 2004.

MENDONÇA, V.; TOSTA, M.da S.; MACHADO, J.R.; GOULART JUNIOR, S.A.R.; TOSTA, J. da S.; BISCARO, G.A. Fertilizante de liberação lenta na formação de mudas de maracujazeiro-amarelo. Ciência e Agroetecnologia, v.31, p.344-348, 2007.

PEREIRA, W.E.; LIMA, S.F. de; PAULA, L.B. de; ALVAREZ V., V.H. Crescimento e composição mineral de mudas de maracujazeiro em função de doses de osmocote em dois tipos de substratos. Ceres, V.47, p.311-324, 2000.

REGHIN, M.Y.; OTTO, R.F.; OLINIK, J.R.; JACOBY, C.F.S. Viabilidade do sistema de produção de mudas em bandejas em três cultivares de cebola. Ciência e Agrotecnologia, v.31, p.1075-1084, 2007.

RODRIGUES, A.R.; ALVES J.M.A.; UCHÔA, S.C.P.; ALBUQUERQUE, J. de A.A. de; RODRIGUES, G.S.; BARROS, M.M. Avaliação da capacidade de enraizamento, em água, de brotações, ponteiros e estacas herbáceas de clones de mandioca de mesa.Agro@mbiente On-line, v.2, p.37-45, 2008.

SCIVITTARO, W.B.; OLIVEIRA, R.P. de; RADMANN, E.E. Doses de fertilizante de liberação lenta na formação do porta-enxerto 'Trifoliata'. Revista Brasileira de Fruticultura, v.26, p.520-523, 2004.

TEIXEIRA, P.C.; RODRIGUES, H.S.; LIMA, W.A.A. de; ROCHA, R.N.C. da; CUNHA, R.N.V. da; LOPES, R. Influência da disposição dos tubetes e da aplicação de fertilizantes de liberação lenta, durante o pré-viveiro, no crescimento de mudas de dendezeiro (Elaeis guineensis Jacq.). Ciência Florestal, v.19, p.157-168, 2009.

YAMANISHI, O.K.; FAGUNDES, G.R.; MACHADO FILHO, J.A.; VALONE, G. de V. Efeito de diferentes substratos e duas formas de adubação na produção de mudas de mamoeiro. Revista Brasileira de Fruticultura, v.26, p.276-279, 2004.

Recebido em 20 de fevereiro de 2011 e aprovado em 2 de agosto de 2011 